\title{
Zuständigkeit der Länder für den Strafvollzug? Ehemalige Justizminister fordern Überdenken der Föderalismusreform

\author{
Anne Lütkes
}

35 von 69 Stimmen müssten im Bundesrat gegen eine Änderung der Zuständigkeiten beim Strafvollzug abgegeben werden. Wenn die Länder, in denen die FDP mitregiert, sich von Kubickis Argumenten, die wir in diesem Heft als Standpunkt abdrucken, beeindrucken lassen, und wenn Schleswig-Holstein seinen Landtagsbeschluss vom 17.12.2005 umsetzt, steigen die Chancen. Noch kann sich der Justizminister von Baden-Würtemberg, Herr Goll (FDP), nicht zu einem solchen Entschluss durchringen. Aber immerhin: 12 ehemalige Bundes- und Landesminister sprechen sich gegen diese Pläne aus. Wir drucken exemplarisch im folgenden die Position der ehemaligen Justizministerin des Landes Schleswig-Holstein ab.

$\mathrm{D}$ ie Föderalismusreform wird gegenwärtig ein wenig als Allheilmittel gefeiert. Entflechtung und Stärkung der Länder sind die Zauberworte. Es ist bei der Debatte aber nicht außer Acht zu lassen, dass es im Bundesstaat Deutschland Prinzipien gibt, die eine Bundeszuständigkeit erfordern. Gleichwertige Lebensverhältnisse zu garantieren ist die Aufgabe von Artikel 74 Abs. 1 Nr. 7 des Grundgesetzes und ebenso ist das der Verfassungswille für den Strafvollzug. Einen entsprechenden Antrag hatte Schleswig-Holstein in der Föderalismuskommission bereits vorbereitet. Das Scheitern der Kommission hat diese deutliche Stellungnahme obsolet werden lassen.

Die zunächst gebannt erschienene Gefahr lebt nun wieder auf. Der Vertrag der großen Koalition von Berlin will den Ländern erneut die Zuständigkeit für den Strafvollzug geben. Dies ist hochgefährlich. Die Änderung würde den Ländern die Möglichkeit geben, den Strafvollzug nach Kassenlage zu gestalten. Der Resozialisierungsgedanke bliebe auf der Strecke. Wenn die Mittel für die Straffälligenarbeit dem freien Spiel der Kräfte überlassen werden, ohne Verfassungskorrektur, so hat er letztlich keine Chance mehr - es fehlt ihm stets die politische und öffentliche Unterstützung. Bestrebungen, dem Sicherheitsgedanken im Strafvollzug den Vorrang zu geben, bekämen wieder Aufschwung. Natürlich muss der Strafvollzug kostenbewusst arbeiten. Er tut es auch - aber Haftvermeidung ist hier das entscheidende Stichwort.

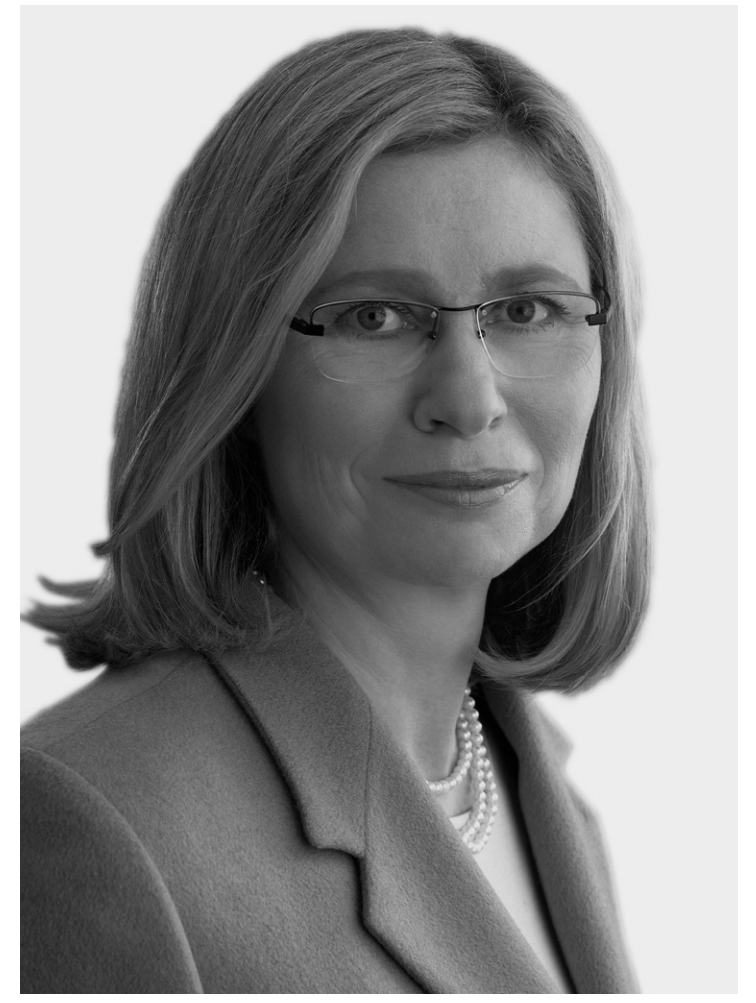

Aber es gibt eben keine regionalen Besonderheiten des Justizvollzugs. Gleichwertige Lebensverhältnisse haben auch für Strafgefangene Verfassungsrang.

Eine demokratische rechtsstaatliche Zivilgesellschaft erkennt man auch an ihrem Umgang mit den Gefangenen. Sicherheit in den Justizvollzugsanstalten ist die eine Aufgabe. Aber Ziel jeglicher Vollzugsarbeit ist die Resozialisierung eines jeden Gefangenen. Die konkurrierende Gesetzgebung nach Artikel 74 Abs. 1 Nr. 1 des Grundgesetzes ist mit Bedacht auf das Strafrecht und den Strafvollzug bezogen, ebenso auf das Recht der Untersuchungshaft und des Jugendstrafvollzugs.

Ich freue mich, dass der SchleswigHolsteinische Landtag dies auch so sieht und sich auf Antrag der Fraktion Bündnis 90/Die Grünen im Dezember einstimmig für eine Beibehaltung der Gesetzgebungskompetenz des Bundes ausgesprochen hat.

Anne Lütkes

Fraktion Bündnis 90/Die Grünen

im Schleswig-Holsteinischen Landtag

Der Vertrag der großen Koalition hat interessanterweise das Recht des Jugendstrafvollzugs und der Untersuchungshaft einheitlich belassen wollen, während der Erwachsenenstrafvollzug offensichtlich in 16 Einzelregelungen gegossen werden soll. Das hat 16 einzelne Kommentierungen zur Folge, 16 Verfassungsgerichte prüfen die Wahrung der Grund- rechte der Gefangenen. Geld, das für Resozialisierungsmaßnahmen benötigt wird, versandet in Bürokratie.

Ich habe mich schon als Landesministerin sehr für eine Föderalismusreform eingesetzt. Dazu gehört natürlich die Übertragung von Gesetzgebungskompetenzen auf die Bundesländer wo es sinnvoll ist. 